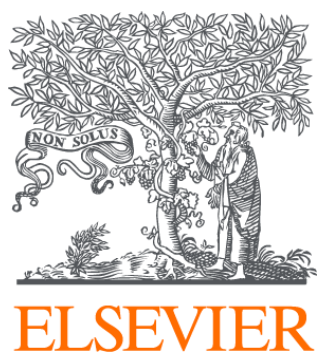

Since January 2020 Elsevier has created a COVID-19 resource centre with free information in English and Mandarin on the novel coronavirus COVID-

19. The COVID-19 resource centre is hosted on Elsevier Connect, the company's public news and information website.

Elsevier hereby grants permission to make all its COVID-19-related research that is available on the COVID-19 resource centre - including this research content - immediately available in PubMed Central and other publicly funded repositories, such as the WHO COVID database with rights for unrestricted research re-use and analyses in any form or by any means with acknowledgement of the original source. These permissions are granted for free by Elsevier for as long as the COVID-19 resource centre remains active. 
Letter to the Editor

\section{Regional differences in use of immune-modulating catechins should be investigated regarding COVID-19}

Dear Editor, Brain, Behavior and Immunity,

I read with interest the in-press article, "The impact of nutrition on COVID-19 susceptibility and long-term consequences" by Butler and Barreintos. As noted, obesity is an important risk factor regarding COVID-19. Obesity itself is a pro-inflammatory condition. While Butler focused on consuming fats and $T$-cell activity as mediators, other possible mechanisms exist. Because excessive cascading release of inflammatory cytokines (cytokine storm) plays a role in mortality versus recovery, tristetraprolin (TTP/aka ZFP36) may be an important specific mediator. A sex difference in ZFP26 allele's correlation to glucose levels (Bouchard et al., 2007) is interesting given that sex differences in COVID-19 risk are emerging. Although beyond the scope of this letter, the effect of TTP on the decay of tumor necrosis factor (TNF, key inflammatory cytokine) has been well-detailed, including by comparing the response of wild-type and TTP knock-out mice to TNF-exposure. Decay of TNF-transcripts slows when TTP is deficient, and the goldstandard knock-out model technique points squarely to TTP function. In sum, TTP plays a primary role in helpfully regulating the response to TNF release when the immune cells respond to a viral invasion, and its role has been well-characterized (Qiu et al., 2015).

TTP expression is affected by dietary substances, such as cinnamon polyphenol extract, and green tea extracts (Cao et al., 2007). Although clinical trials are obviously needed to establish causal relationship specific to COVID-19, this is not the same as knowing nothing. We can say:

1. Obesity is a risk factor for COVID-19 complications.

2. Obesity is a pro-inflammatory condition.

3. A run-away inflammatory response (cytokine storm) has been found to differentiate severe cases.
Therefore inflammation appears important in understanding COVID-19 reactions. The following might be important:

1. A high rate of mortality occurs in some locations (Italy, U.S.) but not others (e.g. Taiwan, Japan).

2. TTP regulates cytokine response to pro-inflammatory stimuli.

3. There is a body of research on substances that impact TTP.

China, Indonesia and Japan are the top consumers of green tea, and persons in Europe, USA, and Africa seldom drink green tea. Death rates by selected country are listed in Table 1 .

Butler wrote, "Studies show that consuming healthy foods has a rapid anti-inflammatory effect, even in the presence of obesity pathology" and it is "critical to consider the impact of ... unhealthy diets on the susceptibility to COVID-19 and recovery." Absolutely. Let's extend this to considering mechanisms and which food cofactors are most important to specific needs. Research in main-stream journals has documented the mechanisms underlying food-based substances' antiviral effects. This is not new, it is not trendy: it is the data (Song et al., 2007; Ide et al., 2016). Although it is not incorrect to state there is no evidence food-based substances have any effect on Covid-19, this is because it's a novel virus that emerged a few months ago. Conversely, it is incorrect to say there is no evidence these substances possess antiviral activity relevant to flu viruses, corona viruses, and immunity (Song et al., 2007; Ide et al., 2016).

Wash your hands, and eat well (as Butler articulates), but also be aware of the strong research on specific substances found in specific foods with attention to the mechanisms of their antiviral actions. 
Table 1

COVID deaths per capita. Countries with more than 100 total deaths are included. The 10 countries with the highest death rates as of June 26, 2020 (10) are listed along with three countries that consume high levels of green tea.

\begin{tabular}{lll}
\hline Country & Number of COVID Deaths & COVID Deaths/100 K POP. \\
\hline Belgium & 9,726 & 85.15 \\
United Kingdom & 43,314 & 65.14 \\
Spain & 28,330 & 60.63 \\
Italy & 34,678 & 57.38 \\
Sweden & 5,230 & 51.36 \\
France & 29,755 & 44.42 \\
United States & 124,410 & 38.03 \\
Ireland & 1,727 & 35.58 \\
Netherlands & 6,119 & 35.51 \\
Peru & 8,761 & 27.39 \\
Japan & 971 & 0.77 \\
China & 4,641 & 0.33 \\
Indonesia & 2,620 & 0.98 \\
\hline
\end{tabular}

\section{Appendix A. Supplementary data}

Supplementary data to this article can be found online at https:// doi.org/10.1016/j.bbi.2020.07.012.

\section{References}

Bouchard, L., Vohl, M.C., Deshaies, Y., Rhéaume, C., Daris, M., Tchernof, A., 2007. Visceral adipose tissue zinc finger protein 36 mRNA levels are correlated with insulin, insulin resistance index, and adiponectinemia in women. Eur. J. Endocrinol. 157 (4), 451-457. https://doi.org/10.1530/EJE-07-0073.

Qiu, L.Q., Lai, W.S., Bradbury, A., Zeldin, D.C., Blackshear, P.J., 2015. Tristetraprolin (TTP) coordinately regulates primary and secondary cellular responses to proinflammatory stimuli. J. Leukoc. Biol. 97 (4), 723-736. https://doi.org/10.1189/jlb. 3A0214-106R.

Cao, H., Kelly, M.A., Kari, F., Dawson, H.D., Urban Jr, J.F., Coves, S., Roussel, A.M., Anderson, R.A., 2007. Green tea increases anti-inflammatory tristetraprolin and decreases pro-inflammatory tumor necrosis factor mRNA levels in rats. J. Inflamm. 4 (1). https://doi.org/10.1186/1476-9255-4-1.

Song, J.M., Park, K.D., Lee, K.H., et al., 2007. Biological evaluation of anti-influenza viral activity of semi-synthetic catechin derivatives. Antiviral. Res. 76 (2), 178-185. https://doi.org/10.1016/j.antiviral.2007.07.001.

Ide, K., Kawasaki, Y., Kawakami, K., Yamada, H., 2016. Anti-influenza virus effects of catechins: a molecular and clinical review. Curr. Med. Chem. 23 (42), 4773-4783. https://doi.org/10.2174/0929867324666161123091010.

M. Catherine DeSoto Department of Psychology, University of Northern Iowa, Cedar Falls, IA, United States

E-mail address: cathy.desoto@uni.edu.

*Address: Department of Psychology, University of Northern Iowa, Cedar Falls, Iowa 50614-0505, Bartlett 2062, United States. 